\title{
Unequal morph frequencies in populations of tristylous Lythrum salicaria (Lythraceae) from southern Sweden
}

\author{
STEFAN ANDERSSON \\ Department of Systematic Botany, University of Lund, O. Vallgatan 18-20, S-223 61 Lund, Sweden
}

\begin{abstract}
Style morph frequencies in tristylous Lythrum salicaria were determined along the shore of a lake in South Sweden. The results indicated a significant deviation from equal morph frequencies, with the $\mathrm{S}$ morph having a lower frequency than the $\mathrm{L}$ morph and the $\mathrm{M}$ morph being intermediate but there was no tendency for the $\mathrm{S}$ morph to be subject to local loss more frequently than the other morphs, as would be expected if genetic drift were responsible for the deviation seen at the regional level. The linear distribution of the habitat and the presence of all three morphs even in small clusters of plants indicate extensive gene flow with seedlings recruited from the same pool of water-dispersed genotypes. Morph-specific differences in fitness or self-fertilization may be more important than random processes in determining morph frequencies in this region and in other areas with a similar population structure.
\end{abstract}

Keywords: floral polymorphism, genetic drift, Lythrum salicaria, population size, tristyly.

\section{Introduction}

Trimorphic heterostyly (tristyly), a floral polymorphism with individuals classified as long, mid or short, depending on the length of the style, has received considerable interest in evolutionary studies of plant breeding systems (Weller, 1976; Charlesworth, 1979; Barrett et al., 1989), gender specialization (Casper \& Charnov, 1982; Nicholls, 1987; Kohn \& Barrett, 1992; O'Neil, 1992) and stochastic processes in small and isolated populations (Barrett et al., 1989; Eckert \& Barrett, 1992). In addition to the floral differences which promote inter-morph pollen transfer, a physiological incompatibility mechanism ensures that fertilization largely takes place between plants of different morphs, at least in some tristylous species (Darwin, 1877). In large populations with equal style-morph fitnesses, this leads to negative frequency-dependent selection and a stable equilibrium state where the three flower morphs are equally frequent (Fisher, 1965; Heuch, 1979a, b), while unequal representation is expected when the morphs differ in fitness or selfing rate (Schoch-Bodmer, 1938; Charlesworth, 1979; Heuch, 1979a, b) and when the populations are sufficiently small for founder events or population bottlenecks to override the effect of selection (Heuch, 1980; Barrett et al., 1989; Eckert \& Barrett, 1992).
According to recent computer simulations (Heuch, 1980; Barrett et al., 1989; Eckert \& Barrett, 1992; Husband \& Barrett, 1992), random genetic drift in small and isolated populations results in a distinct pattern of morph loss with the short-styled morph (S) being lost more frequently than the mid-styled $(\mathbf{M})$ and long-styled ( $\mathrm{L}$ ) morphs and the $\mathrm{M}$ morph being lost more frequently than the $\mathrm{L}$ morph. As noted by Heuch (1980), this is a manifestation of the two-locus genetic system involved in the polymorphism; the stochastic loss of the allele that determines a given morph type is inversely related to its equilibrium frequency (Fisher, 1965), which is lowest for the dominant $S$ allele (expressing the $\mathrm{S}$ morph irrespective of the genotype at the $M$ locus), intermediate for the dominant $M$ allele (expressing the $\mathrm{M}$ morph when the $S$ allele is absent) and highest for the recessive $s$ and $m$ alleles (expressing the $\mathrm{L}$ morph when both are homozygous). The stochastic loss of the $\mathrm{S}$ morph and to a lesser extent the $\mathrm{M}$ morph is most frequent in populations that comprise less than 30 plants whereas the L morph can be maintained in quite small populations but there is no consistent bias in the morph frequencies within those populations that remain tristylous. These predictions hold regardless of whether inheritance is disomic (Barrett et al., 1989; Eckert \& Barrett, 1992; Husband \& Barrett, 1992) or tetrasomic (Heuch, 1980). 
Results obtained in a Canadian survey of morph frequencies in the tristylous Lythrum salicaria revealed an overall deficiency of the $S$ morph due to the frequent loss of this morph in the smallest populations (Eckert \& Barrett, 1992), implying that stochastic effects in genetically isolated populations play a major role in determining the morph frequency variation in this recently colonized area. However, as pointed out by Eckert \& Barrett (1992), many regional populations in the indigenous range (Europe) show similar deviations from isoplethy without (apparent) loss of the $\mathrm{S}$ morph at the local level (Haldane, 1936; Schoch-Bodmer, 1938; Hoeg, 1944; Halkka \& Halkka, 1974; Heuch, 1979a), suggesting that deterministic factors may be more important in the native area or that (sub)populations lacking the S morph were included in the European samples. To distinguish between these hypotheses, it is necessary to determine the morph structure in populations spanning the full range of sizes. In the present study, I report morph frequencies of Lythrum salicaria in a restricted area of South Sweden and examine whether any deviation from isoplethy in the regional sample is caused by the absence of the rarest morph $(\mathrm{s})$ in spatially separated patches of individuals.

\section{Material and methods}

The purple loosestrife, Lythrum salicaria L. (Lythraceae; hereafter Lythrum), is a herbaceous perennial that occurs in a wide variety of wetland habitats, both in the native Eurasian range and in the northeastern parts of North America where the species occurs as a naturalized weed. The plants lack extensive clonal propagation and reproduce through seed. Lythrum shows tetrasomic inheritance (Fisher \& Martin, 1947; Fyfe, 1953) and possesses a typical tristylous breeding system (Darwin, 1877), controlled by a two-locus genetic system with epistasis (Fisher \& Mather, 1943).

The data set in the present study was obtained in the summer of 1983 when I searched parts of the northern shore of Lake Rusken (including five islands) in the district of Småland, South Sweden (Fig. 1) for flowering plants of Lythrum and determined the style morph for all plants encountered. The plants were confirmed to a narrow zone along the lake margin and rarely formed dense stands, making it easy to distinguish separate genets. Even in large two-dimensional populations, most plants formed distinct clumps of ramets, allowing a complete count of genetic individuals. To reveal small-scale differentiation in the morph structure at the lowest possible group level, I recorded whether a plant occurred singly or in a small patch of individuals and counted the plants in each patch. The study was carried out in late July when all plants were in full bloom. Heterogeneity in the proportion of morphs among subsamples was assessed using contingency tests whereas the fit to predicted frequencies (see below) was examined by means of chi-square procedures. Based on the relative position of each plant or cluster of plants along the shore, I treated the population as a linear sequence of observations and employed a runs test to determine whether morph loss (if any) showed any spatial structure at the local level (Sokal \& Rohlf, 1981).

\section{Results and discussion}

A total of 2001 flowering plants was recorded along the northern shore of Lake Rusken and on the five offshore islands. The plants were spread over approximately $9 \mathrm{~km}$, with an average distance of $10 \mathrm{~m}$ between each occurrence of Lythrum (defined as an individual plant or a cluster of plants). In agreement with previous population surveys in Canada (Eckert \& Barrett, 1992), England (Haldane, 1936), Switzerland (SchochBodmer, 1938), Germany (Heuch, 1979a), Norway (Hoeg, 1944) and Finland (Halkka \& Halkka, 1974), there was a highly significant deviation from isoplethy $\left\langle\chi^{2}{ }_{(2)}=34.5, P<0.001\right)$, with an excess of the $\mathrm{L}$ morph (37.3 per cent), a deficiency of the $S$ morph $(27.2$ per cent) and the $\mathrm{M}$ morph being intermediate (35.5 per cent).

I found no spatial heterogeneity in the frequency of morphs when the area was divided into 11 linear sections and three large two-dimensional stands with more than 60 individuals (Fig. 1, Table 1; $\chi_{(26)}^{2}=31.6$, $P=0.207)$ and there were no consistent differences among subsamples within either of these categories (among sections: $\chi_{(20)}^{2}=26.70, \quad P=0.144$; among stands: $\left.\chi^{2}{ }_{(4)}=3.77, P=0.439\right)$ or between these two categories $\left(\chi_{(2)}^{2}=1.1, P=0.589\right.$; plants pooled across subsamples), both of which showed similar deviations from isoplethy as the overall sample (sections: L 37.1 per cent, M 35.2 per cent, S 27.7 per cent, $\chi_{(2)}^{2}=23.68, P<0.001$; stands: $\mathrm{L} 38.5$ per cent, $\mathrm{M}$ 36.4 per cent, $S 25.1$ per cent, $\left.\chi_{(2)}^{2}=11.82, P=0.005\right)$. Hence, there was little evidence for a broad-scale association between geographical location, population structure and morph frequency variation in this area.

The lack of regional differences in the frequency of the flower morphs is indicative of predominant gene flow and suggests little potential for stochastic factors to operate at this level. However, local irregularities in the morph frequency may go unnoticed when the data represent a combined sample from genetically isolated (sub)populations (Heuch, 1980), as might have been the case in earlier European studies (Eckert \& Barrett, 
Fig. 1 Map showing the study area divided into 11 linear sections, with the locations of three larger populations marked with arrows.

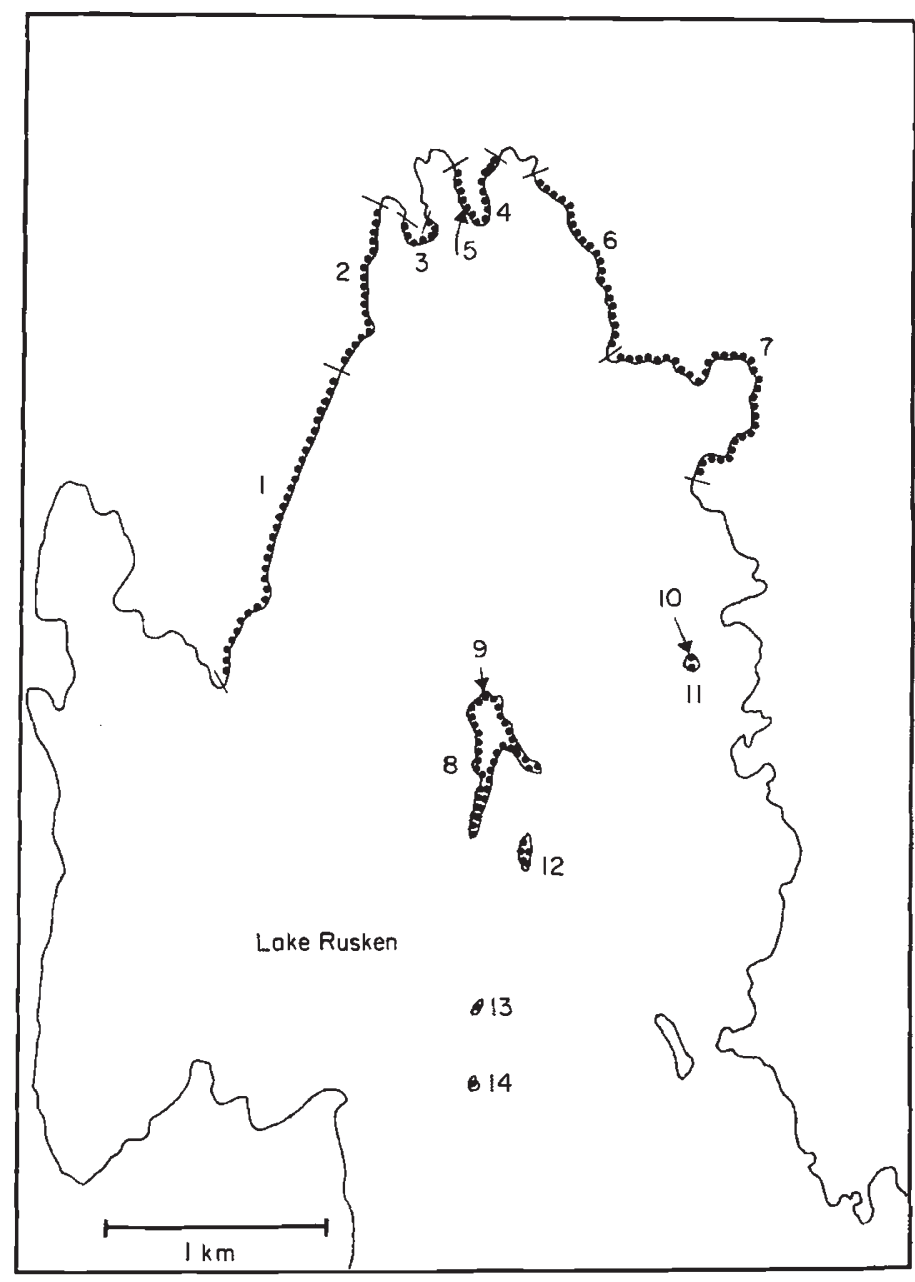

Table 1 Frequency of the three style morphs in regional subsamples (see Fig. 1)

\begin{tabular}{llrrr}
\hline Subsample & $\begin{array}{l}\text { Population } \\
\text { structure }\end{array}$ & L & M & \multicolumn{1}{c}{ S } \\
\hline 1 & Linear & 22 & 37 & 19 \\
2 & Linear & 52 & 40 & 31 \\
3 & Linear & 11 & 15 & 11 \\
4 & Linear & 56 & 46 & 59 \\
5 & Two-dimensional & 30 & 21 & 12 \\
6 & Linear & 52 & 53 & 34 \\
7 & Linear & 113 & 113 & 106 \\
8 & Linear & 188 & 172 & 124 \\
9 & Two-dimensional & 90 & 89 & 60 \\
10 & Two-dimensional & 27 & 29 & 24 \\
11 & Linear & 20 & 24 & 21 \\
12 & Linear & 6 & 7 & 5 \\
13 & Linear & 40 & 30 & 16 \\
14 & Linear & 40 & 33 & 23 \\
Sum & & 747 & 709 & 545 \\
& & & &
\end{tabular}

1992): To determine whether local loss could account for the overall deficiency of the $\mathrm{S}$ morph in the present study, I extended the analysis to 216 spatially isolated patches of individuals, 83 per cent of which consisted of five or fewer plants (the mean and median patch size was six and two plants, respectively).

Table 2 shows the observed frequency of monomorphic, dimorphic and trimorphic patches with $N=2-10$ individuals (larger patches were always trimorphic, data not shown). Contrary to the prediction that random genetic drift determines the morph structure when populations consist of fewer than 20 individuals (Heuch, 1980; Eckert \& Barrett, 1992), there was little evidence of local morph loss in the current study: patches with more than five individuals remained trimorphic in nearly all cases and only those with fewer than four individuals occasionally lacked one or two morphs (Table 2). There was no tendency for the $S$ morph to be absent from more patches than the other morphs, as would be the case if stochastic loss 
Table 2 Morph structure in groups with two to ten plants. Values in bold are the frequencies predicted under the assumption that each patch is a sample drawn from the same regional pool of genotypes (based on a trinomial distribution with morph ratios determined from the overall sample, see text). Observed and predicted values in the monomorphic and dimorphic categories were pooled in the calculation of $\chi^{2}$ for patches with four or more plants. All $\chi^{2}$ values are nonsignificant $(P \gg 0.05)$, indicating a close fit between observed and predicted frequencies

\begin{tabular}{|c|c|c|c|c|c|c|c|c|c|c|c|c|c|c|}
\hline \multirow{2}{*}{$\begin{array}{l}\text { No. of plants } \\
\text { in patch }\end{array}$} & \multicolumn{6}{|c|}{ Monomorphic } & \multicolumn{6}{|c|}{ Dimorphic } & \multicolumn{2}{|c|}{ Trimorphic } \\
\hline & $\mathrm{L}$ & & M & & $\mathrm{S}$ & & LM & & LS & & MS & & LMS & $\chi^{2}$ (d.f.) \\
\hline 2 & 16 & 15.5 & 12 & 13.9 & 11 & 8.2 & 28 & 29.4 & 26 & 22.6 & 18 & 21.4 & -- & $2.3_{\langle 5\rangle}$ \\
\hline 3 & 2 & 2.1 & 2 & 1.8 & & 0.8 & 12 & 11.8 & 8 & 8.1 & 8 & 7.4 & 68.9 & $6.7_{(6)}$ \\
\hline 4 & 0 & 0.4 & 2 & 0.3 & & 0.1 & 3 & 4.9 & 3 & 3.0 & 4 & 2.7 & $8 \mathbf{8 . 7}$ & $1.8_{(2)}$ \\
\hline 5 & 0 & 0.1 & 0 & 0 & 0 & 0 & 1 & 1.5 & 2 & 0.8 & 1 & 0.7 & 44.8 & $0.5_{(2)}$ \\
\hline 6 & 0 & $\mathbf{0}$ & 0 & $\mathbf{0}$ & 0 & $\mathbf{0}$ & 0 & 0.7 & 0 & 0.3 & 1 & 0.3 & 43.6 & $0.1_{(2)}^{(2)}$ \\
\hline 7 & 0 & $\mathbf{0}$ & 0 & $\mathbf{0}$ & 0 & $\mathbf{0}$ & 1 & 0.5 & 0 & 0.2 & 0 & 0.2 & 44.1 & $0.0_{(2)}$ \\
\hline 8 & 0 & $\mathbf{0}$ & 0 & $\mathbf{0}$ & 0 & $\mathbf{0}$ & 0 & 0.2 & 0 & 0.1 & 0 & 0.1 & 32.6 & $0.5_{(2)}$ \\
\hline 9 & 0 & $\mathbf{0}$ & 0 & $\mathbf{0}$ & 0 & $\mathbf{0}$ & 0 & 0.1 & 0 & $\mathbf{0}$ & 0 & 0 & 21.8 & $0.2_{(2)}$ \\
\hline 10 & 0 & 0 & 0 & $\mathbf{0}$ & 0 & $\mathbf{0}$ & 0 & 0.2 & 0 & 0.1 & 0 & $\mathbf{0}$ & 43.7 & $0.3_{(2)}$ \\
\hline
\end{tabular}

accounted for the overall deficiency of the S morph. Moreover, the absence of the $\mathrm{S}$ morph showed little spatial pattern when each of the sections in Fig. 1 was treated as a linear sequence of observations, with each occurrence of Lythrum classified into whether the S morph was present or absent (runs test, Table 3).

It is conceivable that many plants establish from a common pool of water-dispersed propagules, considering the buoyant seedlings of Lythrum (Sculthorpe, 1967) and the sparse and scattered occurrence of the species along the lake margin, a scenario that also applies to the Finnish island populations studied by Halkka \& Halkka (1974). Hence, instead of regarding the regional population as a series of genetically isolated subpopulations, it may be more useful to consider groups of plants as samples drawn from the same underlying population of genotypes, a process that could account for the occasional 'loss' of morphs in the smallest patches. This idea was tested by using the trinomial distribution:

$P=(n ! /(l ! m ! s !)) p_{\mathrm{L}}^{1} p_{\mathrm{M}}^{\mathrm{m}} p_{S}^{\varsigma}$,

where $P$ is the probability of getting $l$ plants of the long-styled morph, $m$ plants of the mid-styled morph and $s$ plants of the short-styled morph, in a sample of $n$ individuals from a regional population in which the morph frequencies are $p_{\mathrm{L}}, p_{\mathrm{M}}$, and $p_{\mathrm{S}}$ (see above). As the observed morph structure is expressed as the frequency of patches with one, two or three morphs (Table 2), I combined the calculated $P$ values of all possible outcomes in each of these categories. For example, the expected frequency of dimorphic clusters with four individuals of the $L$ or $M$ morph was obtained as the sum of $P$ (LMMM), $P$ (LLMM) and $P$
Table 3 Number of occurrences of Lythrum (single individuals or patches of plants) with $(+S)$ and without $(-S)$ the $\mathrm{S}$ morph and the number of runs (sequences of one or more like elements preceded or followed by unlike elements) for each of the 11 linear sections in Fig. 1

\begin{tabular}{lcrc}
\hline Subsample & $+S$ & $-S$ & No. of runs \\
\hline 1 & 16 & 30 & 16 \\
2 & 24 & 63 & 37 \\
3 & 11 & 21 & 16 \\
4 & 43 & 52 & 39 \\
6 & 34 & 70 & 48 \\
7 & 74 & 129 & 87 \\
8 & 93 & 152 & 106 \\
11 & 12 & 6 & 9 \\
12 & 5 & 11 & 6 \\
13 & 8 & 14 & 9 \\
14 & 6 & 9 & 9 \\
\hline
\end{tabular}

The probability of getting the observed number of runs by chance exceeded 0.05 in all cases, suggesting random linear arrangement of sites with and without the S morph.

(LLLM), where each $P$ value refers to the probability of obtaining the style morphs shown in the parentheses. I found a fairly close correspondence between the observed number of monomorphic, dimorphic and trimorphic patches and the frequencies expected under the assumption that groups of plants represent samples from the same pool of genotypes (Table 2, values in bold), implying that the absence of one or two morphs 
in some of the smallest patches is a sampling effect associated with seedling recruitment rather than a consequence of genetic drift in established (sub)populations.

The maintenance of all three morphs even in small clusters of plants and the seemingly random arrangement of sites with and without the minority morph are not in accord with stochastic models of morph loss like those proposed by Heuch (1980), Barrett et al. (1989), Eckert \& Barrett (1992) and Husband \& Barrett (1992). To the extent that patterns seen in the present study also apply to other European populations, most of which show a similar deficiency of the S morph (see above), it may be necessary to invoke selective forces to account for the unequal representation of the three style morphs in at least some of these regions, a conclusion that also applies to the deficiency of the $M$ morph in trimorphic populations in Canada (Eckert \& Barrett, 1992) and northern Sweden (J. Agren, unpublished data). Possible candidates include morph-specific differences in vegetative propagation (Schoch-Bodmer, 1938), male and female fertility (Darwin, 1877; Barrett et al., 1989; O'Neil, 1992), seed quality (Nicholls, 1987) and selfing rate (Stout, 1923; Schoch-Bodmer, 1938; Charlesworth, 1979), although Heuch (1979b) demonstrated that unrealistically large differences in the rate of self-fertilization would be required to explain the observed deviations in the European samples. Only field experiments can reveal the deterministic or stochastic factors acting against the $S$ morph in the native range of the species.

\section{Acknowledgements}

I thank Spencer Barrett for valuable comments on the manuscript and the Swedish Natural Science Research Council for financial support during the preparation of this paper (postdoctoral fellowship).

\section{References}

BARRETT; S. C. H., MORGAN, M. T. AND HUSBAND, B. C. 1989. The dissolution of a complex genetic polymorphism: the evolution of self-fertilization in tristylous Pontederia paniculata (Pontederiaceae). Evolution, 43, 1398-1416.

CASPER, B. B. AND CHARNOV, E. L. 1982. Sex allocation in heterostylous plants. J. Theor, Biol., 96, 143-149.

CHARLESWORTH, D, 1979. The evolution and breakdown of tristyly. Evolution, 33, 488-498.
DARWIN, C. 1877. The Different Forms of Flowers on Plants of the Same Species. John Murray, London.

ECKERT, C. G. AND BARRETT, S. C. H. 1992. Stochastic loss of style morphs from populations of tristylous Lythrum salicaria and Decodon verticillatus (Lythraceae). Evolution, 46, 1014-1029.

FISHER, R. A. 1965. The Theory of Inbreeding, 2nd edn. Oliver and Boyd, Edinburgh.

FISHER, R. A. AND MARTIN, V. C. 1947. Spontaneous occurrence in Lythrum salicaria of plants duplex for the short-style gene. Nature, 160, 541 .

FISHER, R. A. AND MATHER, K. 1943. The inheritance of style length in Lythrum salicaria. Ann. Eugen., 12, 1-23.

FYFE, V. C. 1953. Double reduction at the Mid locus in Lythrum salicaria. Heredity, 7, 285-292.

HALDANE, J. B. S. 1936. Some natural populations of Lythrum salicaria. J. Genet., 32, 393-397.

HALKKA, O. AND halKKa, L. 1974. Polymorphic balance in small island populations of Lythrum salicaria. Ann. Bot. Fenn., 11, 267-270.

HEUCH, I. 1979a. Equilibrium populations of heterostylous plants. Theor. Pop. Biol., 15, 43-57.

HEUCH, I. 1979b. The effect of partial self-fertilization on type frequencies in heterostylous plants. Ann. Bot., 44, 611-616.

HEUCH, I. 1980. Loss of incompatibility types in finite populations of the heterostylous plant Lythrum salicaria. Hereditas, 92, 53-57.

HOEG, O. A. 1944. The ratios of different forms of flowers in Lythrum salicaria in Norway. Blyttia, 2, 71-74.

HUSBAND, B. C. AND BARRETT, S. C. H. 1992. Genetic drift and the maintenance of the style length polymorphism in tristylous populations of Eichhornia paniculata (Pontederiacea). Heredity, 69, 440-449.

KOHN, J. R. AND BARRETT, S. C. H. 1992. Experimental studies on the functional significance of heterostyly. Evolution, 46, 43-55.

NICHOLLS, M. s. 1987. Pollen flow, self-fertilization and gender specialization: factors affecting seed-set in the tristylous species Lythrum salicaria. Plant. Syst. Evol., 156, $151-157$.

O'NEIL, P. 1992. Variation in male and female reproductive success among floral morphs in the tristylous plant Lythrum salicaria. Am. J. Bot., 79, 1024-1030.

SCHOCH-BODMER, H. 1938. The proportion of long-, mid- and short-styled plants in natural populations of Lythrum salicaria. J. Genet., 36, 39-43.

sCUlthorpe, c. D. 1967. The Biology of Aquatic Vascular Plants. St. Martins's Press, New York.

SOKAL, R. R. AND ROHLF, F. J. 1981. Biometry, 2nd edn. Freeman, San Francisco.

STouT, A. B. 1923. Studies of Lythrum salicaria. I. The efficiency of self-pollination. Am. J. Bot., 10, 440-449.

WELLER, S. C. 1976. Breeding system polymorphism in a heterostylous species. Evolution, 30, 442-454. 